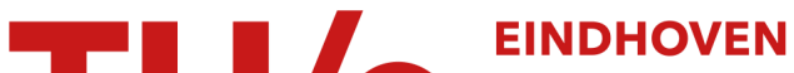 \\ UNIVERSITY OF \\ TECHNOLOGY
}

\section{Determination of Injection Barriers in Organic Semiconductor Devices from Capacitance Measurements}

\section{Citation for published version (APA):}

Mensfoort, van, S. L. M., \& Coehoorn, R. (2008). Determination of Injection Barriers in Organic Semiconductor Devices from Capacitance Measurements. Physical Review Letters, 100(8), 086802-1/4. [086802].

https://doi.org/10.1103/PhysRevLett.100.086802

DOI:

10.1103/PhysRevLett.100.086802

Document status and date:

Published: 01/01/2008

\section{Document Version:}

Publisher's PDF, also known as Version of Record (includes final page, issue and volume numbers)

\section{Please check the document version of this publication:}

- A submitted manuscript is the version of the article upon submission and before peer-review. There can be important differences between the submitted version and the official published version of record. People interested in the research are advised to contact the author for the final version of the publication, or visit the $\mathrm{DOI}$ to the publisher's website.

- The final author version and the galley proof are versions of the publication after peer review.

- The final published version features the final layout of the paper including the volume, issue and page numbers.

Link to publication

\section{General rights}

Copyright and moral rights for the publications made accessible in the public portal are retained by the authors and/or other copyright owners and it is a condition of accessing publications that users recognise and abide by the legal requirements associated with these rights.

- Users may download and print one copy of any publication from the public portal for the purpose of private study or research.

- You may not further distribute the material or use it for any profit-making activity or commercial gain

- You may freely distribute the URL identifying the publication in the public portal.

If the publication is distributed under the terms of Article 25fa of the Dutch Copyright Act, indicated by the "Taverne" license above, please follow below link for the End User Agreement:

www.tue.nl/taverne

Take down policy

If you believe that this document breaches copyright please contact us at:

openaccess@tue.nl

providing details and we will investigate your claim. 


\title{
Determination of Injection Barriers in Organic Semiconductor Devices from Capacitance Measurements
}

\author{
S. L. M. van Mensfoort ${ }^{1,2, *}$ and R. Coehoorn ${ }^{1,2}$ \\ ${ }^{1}$ Department of Applied Physics, Eindhoven University of Technology, $5600 \mathrm{MB}$ Eindhoven, The Netherlands \\ ${ }^{2}$ Philips Research Laboratories, High Tech Campus 4, 5656 AE Eindhoven, The Netherlands
}

(Received 9 July 2007; published 26 February 2008)

\begin{abstract}
The low-frequency differential capacitance of single-carrier (metal/organic semiconductor/metal) devices with a sandwich structure is shown to display a distinct peak if the injection barrier of at least one of the electrodes is sufficiently small. The effect is shown to be caused by the diffusion contribution to the current density. Depending on the height of the injection barriers, the peak voltage can be a few tenths of a volt below the built-in voltage, $V_{\mathrm{bi}}$. We show how the peak voltage and the peak height can be used to accurately determine the injection barriers and $V_{\mathrm{bi}}$, and we demonstrate the method by applying it to polyfluorene-based devices.
\end{abstract}

\section{DOI: 10.1103/PhysRevLett.100.086802}

The transport characteristics of electronic semiconductor devices depends sensitively on the presence of energy barriers for charge carrier injection. In field-effect transistors (FETs), including organic FETs [1] and inorganic Schottky-barrier metal-oxide-semiconductor field-effect transistors (MOSFETs) [2], energy barriers control the charge injection, and thereby strongly influence, e.g., the on/off ratio. Furthermore, injection barriers can limit the luminous efficacy of organic light-emitting diodes (OLEDs) [3] and of organic light-emitting FETs [4]. In organic electronic devices, injection barriers can deviate more than $1 \mathrm{eV}$ from the value that would be expected in the case of vacuum level alignment at the interface, even for clean and flat interfaces [5], and can depend strongly on the preparational conditions [6]. Methods for measuring the injection barriers in devices are often based on a determination of the built-in voltage, $V_{\mathrm{bi}}[7,8]$. For single-carrier hole-only (HO) devices, $e V_{\mathrm{bi}}=\phi_{2}-\phi_{1}$, where $\phi_{1}$ and $\phi_{2}$ are the hole-injection barriers at the two electrodes and $e$ is the elementary charge (see the inset in Fig. 1). If $\phi_{1}$ is known, a measurement of $V_{\mathrm{bi}}$ suffices thus to determine $\phi_{2}$.

In this Letter, we propose an alternative and more direct method for determining the injection barriers at both interfaces that does not require prior knowledge of the value of one of the barriers. The method is based on measurements of the differential capacitance per unit area $(C)$ in the low-frequency $(f)$ regime. We focus on single-carrier [metal/organic semiconductor/metal (MOM)] devices with a sandwich structure. From experiments on MOM devices containing a polyfluorene-based semiconductor, and using extensive modeling, we show that the diffusion contribution to the current density can give rise to a distinct, narrow peak in the low- $f C(V)$ curves. The peak voltage, height, and shape are used to determine the injection barriers, and thereby also $V_{\mathrm{bi}}$. We note that $V_{\mathrm{bi}}$ cannot be determined directly from the onset voltage, $V_{0}$, of the current density $(J)$ versus the voltage $(V)$ curve, as there is no strict onset of the diffusion current. Therefore, $V_{0}$ is not
PACS numbers: 73.40.Sx, 73.61.Ph, 85.30.De

a well-defined quantity. Just as $V_{0}$, the peak voltage $\left(V_{\text {peak }}\right)$ is in general smaller than $V_{\mathrm{bi}}$, but unlike $V_{0}, V_{\text {peak }}$ is conceptually and practically well defined. A peak in the $C(V)$ curves was found earlier by Van Dijken et al. [9] who studied hole-only MOM devices based on poly( $p$-phenylene vinylene) (PPV), and observed a strong dependence of the peak capacitance on the injecting electrode used. Our model provides an explanation for their results.

Figure 1 shows the $C(V)$ curves in the low- $f$ limit for one $\mathrm{HO}$ and two electron-only (EO) MOM devices. Using a Schlumberger SI 1260 impedance analyzer, four point measurements were carried out, with a current and a voltage contact connected to each thin film electrode layer. The rms modulation voltage amplitude was $20 \mathrm{mV}$. The remaining parasitic series resistance and the parasitic capacitance (resulting from the overlap of the electrodes outside the active $3 \times 3 \mathrm{~mm}^{2}$ area) were found to have no significant effect on the measured $C(V)$ curves. The organic semicon-

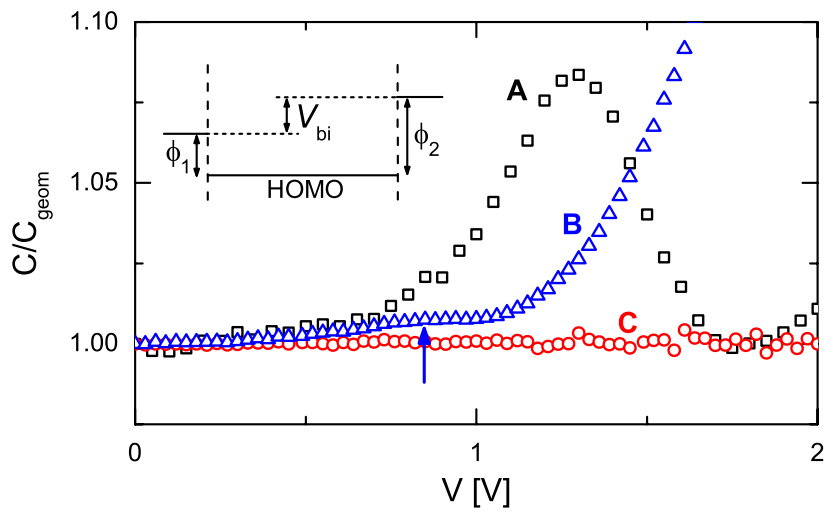

FIG. 1 (color online). Experimental $C(V)$ curves for hole-only $(A)$ and electron-only ( $B$ and $C$ ) devices with structures given in Table I, at $T=295 \mathrm{~K}$ and $f=200 \mathrm{~Hz}$. The inset shows for hole-only devices the injection barriers, defined as the energy difference between the highest occupied molecular orbital (HOMO) and the Fermi level of each electrode. 
ductor is a blue light-emitting polyfluorene(PF)-based polymer. In Ref. [10] an extensive report on the steadystate transport through this polymer is given. The hole transport takes place via copolymerized monomeric units, which facilitate hole injection, whereas the electron transport takes place via PF-derived lowest unoccupied molecular orbital states. The device structures and deposition methods are summarized in Table I.

Figure 1 reveals for the HO device a distinct peak in the $C(V)$ curve, at $1.30 \pm 0.05 \mathrm{~V}$. The peak capacitance, $C_{\text {peak }}$, is approximately $8 \%$ larger than the geometrical capacitance $C_{\text {geom }}=\varepsilon / L$ (with $\varepsilon$ the permittivity and $L$ the organic layer thickness). For the HO devices we will present a full analysis of the frequency dependence of $C(V)$. It is argued in Ref. [10] that for these devices the hole-injection barrier at the anode is small $\left(\phi_{1}<0.2 \mathrm{eV}\right)$, but that there is a large electron injection barrier of $\sim 0.5 \mathrm{eV}$ at the cathode for $\mathrm{EO}$ devices with a Ba-Al cathode. Figure 1 shows that for such devices no peak in the $C(V)$ curve is obtained, but that there is a small peak for EO devices with a LiF-Ca-Al cathode (arrow). For the latter devices the current density is 2 orders of magnitude larger than for the $\mathrm{Ba}-\mathrm{Al}$ devices, which is indicative of a smaller injection barrier. These results show that the occurrence of a peak in the $C(V)$ curves is not restricted to PPV and suggest that it is related to the size of the barrier at the injecting electrode interface.

In order to explain these findings, we adopt the simplest possible approach, viz. by assuming a constant mobility, $\mu$, and by assuming fixed energy barriers and charge carrier densities $\left(n_{i}\right)$ at the interfaces [with $i=1$ (2) at the anode (cathode), respectively]. Assuming thermal equilibrium, $n_{i}$ and $\phi_{i}$ are related by $n_{i}=N_{t} \exp \left[-\phi_{i} /\left(k_{B} T\right)\right]$, where $N_{t}$ is the volume density of molecular sites. The use of more advanced models for injection [11] and for the mobility [12] is straightforward, but beyond the scope of this Letter. The experimental $C(V)$ curves cannot be explained from a drift-only model. For $V<V_{\mathrm{bi}}$, the organic layer would then contain no space charge, so that $C=C_{\text {geom }}$, and for $V>V_{\mathrm{bi}}$, the presence of space charge in the device is well known to lead to $C<C_{\text {geom }}$ (with $C=\frac{3}{4} C_{\text {geom }}$ for $n_{1}=\infty$ ) [13]. We find that the peak in the capacitance is related to

TABLE I. Structures of devices for which the $C(V)$ curves are shown in Fig. 1, with layer thicknesses in nm (in between parentheses). The light-emitting polymer (LEP) layers were deposited by spin coating. The $\mathrm{Pd}$ and $\mathrm{Al}$ electrodes were deposited by vacuum evaporation.

\begin{tabular}{cc}
\hline \hline Device & Layer structure (substrate: glass) \\
\hline $\mathrm{A}$ & $\mathrm{ITO}^{\mathrm{a}} \mid$ PEDOT:PSS \\
$\mathrm{B}$ & $\mathrm{Al}^{\mathrm{c}}(100)|\mathrm{LEP}(100)| \mathrm{Pd}(100)$ \\
$\mathrm{C}$ & $\mathrm{Al}^{\mathrm{c}}$ (30) | LEP (100) | LiF (3) | Ca (5) | Al (100) | Ba (5) | Al (100) \\
\hline \hline
\end{tabular}

${ }^{a}$ Indium-tin-oxide.

${ }^{\mathrm{b}}$ Poly-(3,4-ethylene-dioxythiophene):poly(styrene sulphonic acid).

${ }^{\mathrm{c}}$ The Al anodes are expected to be slightly oxidized. the space charge which is already for $V<V_{\mathrm{bi}}$ present in the device due to the diffusion contribution to the current density. We have carried out systematic numerical studies by solving the drift-diffusion problem using the software package CURRY, developed within Philips Research. In the low- $f$ limit, the shape of the $C(V)$ curves is fully determined by the ratio $e V /\left(k_{B} T\right)$, and by the dimensionless carrier densities at the electrodes $\gamma_{i} \equiv n_{i} / n_{0}$, with $n_{0} \equiv$ $\varepsilon k_{B} T /\left(e^{2} L^{2}\right)$ [14]. The full parameter space can thus be explored by calculating $C(V) / C_{\text {geom }}$ curves as a function of $\gamma_{1}$ and $\gamma_{2}$. For $L=100 \mathrm{~nm}$ and $\varepsilon_{r}=3$ (a typical device), $n_{0}$ equals $4.3 \times 10^{20} \mathrm{~m}^{-3}$ at $300 \mathrm{~K}$. Typically, $N_{t} \sim$ $10^{26}-10^{27} \mathrm{~m}^{-3}$. Then, $\gamma \sim 10^{6}$ for $\phi=0$ and $\gamma \sim 1$ for $\phi=0.35 \mathrm{eV}$.

Figures 2(a)-2(d) show calculated $C(V) / C_{\text {geom }}$ curves along selected lines through the $\left\{\gamma_{1}, \gamma_{2}\right\}$ parameter space [see Fig. 3(a)], in the low- $f$ limit. Figure 3(b) shows the carrier density across the device for selected cases. An overview of the peak capacitances and peak voltages is shown in Figs. 3(c) and 3(d), respectively. For symmetric devices $\left(V_{\mathrm{bi}}=0 \mathrm{~V}\right)$, the capacitance shows a narrow peak at $V=0 \mathrm{~V}$, as revealed by Fig. 2(a), with a height that decreases with increasing injection barrier height. For $\phi=$ $0 \mathrm{eV}$, the height is $1.290 C_{\text {geom }}$. In the large-voltage limit, $C$ approaches then the drift-only value $\frac{3}{4} C_{\text {geom }}$. For $\phi=$ $0.4 \mathrm{eV}$, corresponding here to $\gamma \sim 1$, the peak has vanished.

Figure 2(b) shows a series of $C(V)$ curves for a vanishing first barrier and for an increasing second barrier, i.e., an

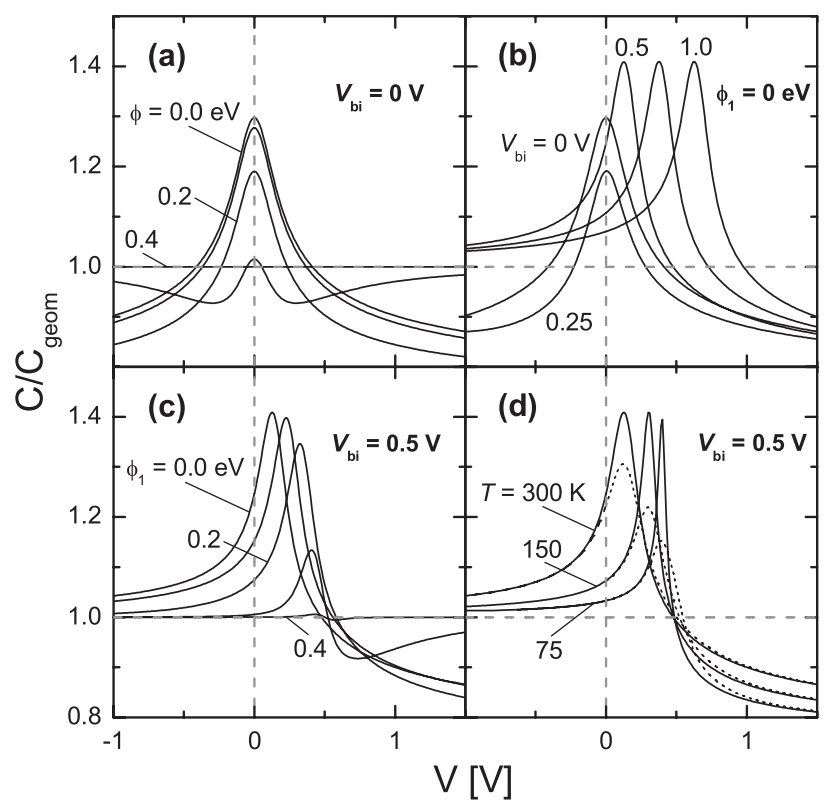

FIG. 2. Calculated $C(V) / C_{\text {geom }}$ curves for devices with $L=$ $100 \mathrm{~nm}, N_{t}=1 \times 10^{27} \mathrm{~m}^{-3}$, and $\varepsilon_{r}=3$, at $T=300 \mathrm{~K}$ and in the low- $f$ limit, for (a) symmetric devices $(0.1 \mathrm{eV}$ steps in $\phi)$, (b) devices with $\phi_{1}=0 \mathrm{eV}$ and a varying built-in voltage (0.25 V steps), and (c) devices with $V_{\mathrm{bi}}=0.5 \mathrm{~V}$, and a varying $\phi_{1}(0.1 \mathrm{eV}$ steps); (d) shows the effect of a temperature variation for $V_{\mathrm{bi}}=0.5 \mathrm{~V}$ (dotted lines: $f=1 \mathrm{kHz}$ ). 


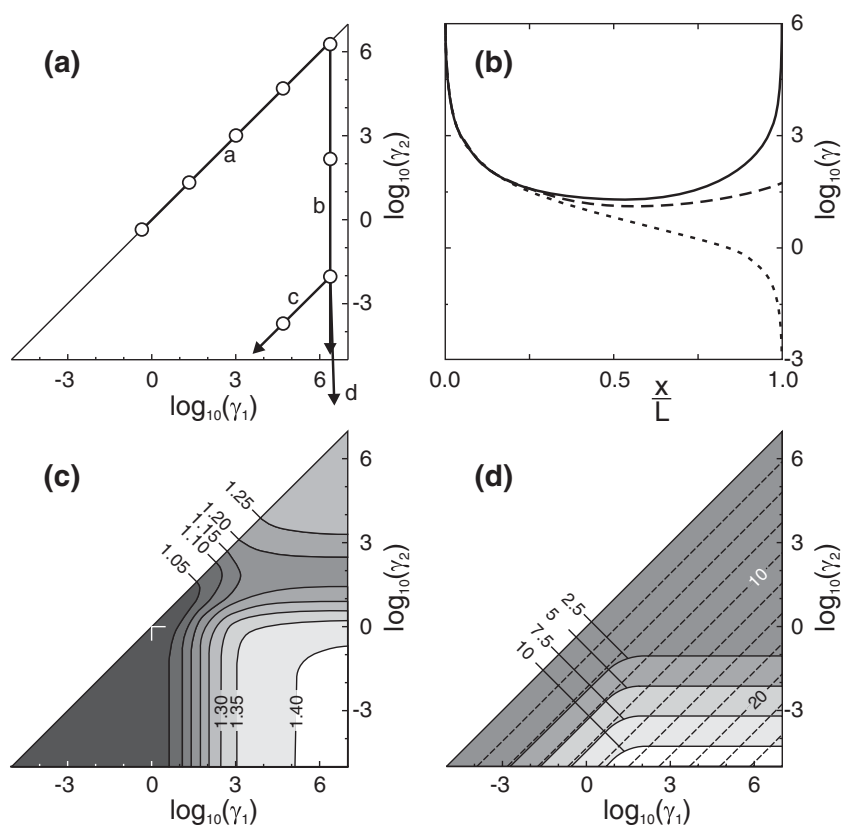

FIG. 3. (a) Lines in the $\left\{\gamma_{1}, \gamma_{2}\right\}$ space corresponding to the parameter variations taken in Figs. 2(a)-2(d); (b) dimensionless charge density at position $x$ across the device at $V_{\text {peak }}$ for $\gamma_{1}=\infty$ and $\gamma_{2}=\infty$ (full curve), $\gamma_{2}=\gamma_{2 \text {,min }}$ (dashed curve), and $\gamma_{2} \rightarrow$ 0 (dotted curve); (c) contours in the $\left\{\gamma_{1}, \gamma_{2}\right\}$ space of equal $C_{\text {peak }} / C_{\text {geom }}$, and (d) of equal $e V_{\text {peak }} /\left(k_{B} T\right)$. Dashed lines: contours of constant $e V_{\mathrm{bi}} /\left(k_{B} T\right)$.

increasing value of $V_{\mathrm{bi}}$. Figure 2(b) reveals a transition between two transport regimes. For small $V_{\mathrm{bi}}$, the peak remains almost fixed at $0 \mathrm{~V}$, and $C_{\text {peak }}$ decreases to a certain minimum value, $C_{\min }=1.175 C_{\text {geom }}$, at $\gamma_{2}=\gamma_{2, \min }$. Figure 3(b) shows that the carrier density is then quite uniform in between the device center and the second electrode, in contrast to the carrier densities in the limits of a very small or very large value of $V_{\mathrm{bi}}$. Beyond this minimum, $C_{\text {peak }}$ and $V_{\text {peak }}$ start to increase, until for large $V_{\text {bi }}$ the peak capacitance becomes constant and $V_{\text {peak }}$ follows $V_{\mathrm{bi}}$ at a fixed distance. We find that then $C_{\text {peak }}=1.405 C_{\text {geom }}$ and that

$$
V_{\mathrm{bi}}-V_{\text {peak }}=\left(\ln \gamma_{1}-a\right) \frac{k_{B} T}{e},
$$

with $a=0.207$. Equation (1) shows that for a strongly asymmetric device with one well-injecting electrode, $V_{\text {peak }}$ can at $295 \mathrm{~K}$ be more than $0.3 \mathrm{eV}$ smaller than $V_{\mathrm{bi}}$.

From Eq. (1) and $e V_{\mathrm{bi}}=k_{B} T \ln \left(\gamma_{1} / \gamma_{2}\right)$, it follows that the injection barrier at the second electrode can be obtained directly from the measured peak position, using

$$
\phi_{2}=e V_{\text {peak }}+\left(\ln \frac{N_{t}}{n_{0}}-a\right) k_{B} T
$$

for the regime for which Eq. (1) is valid (large $\gamma_{1}$ and small $\gamma_{2}$ ). Equations (1) and (2) are the key results of this work. We note that $N_{t}$ is not a priori known, but that even a relatively large uncertainty, of 1 order of magnitude, gives rise to an uncertainty in $\phi_{2}$ of only $\sim 0.1 \mathrm{eV}$.

The dependence of $C$ on the injection barriers, at a relatively large fixed built-in voltage, is shown in Fig. 2(c). As for the case of $V_{\mathrm{bi}}=0 \mathrm{~V}$ [Fig. 2(a)], $C_{\text {peak }}$ is a very sensitive function of $\phi_{1}$. For the conditions assumed, it vanishes already beyond $\phi_{1}>0.4 \mathrm{eV}$. This is consistent with the experimentally observed strong sensitivity of $C_{\text {peak }}$ to the injection barrier (Fig. 1). The peak height and shape can thus be used to determine $\phi_{1}$. The peak shift revealed in Fig. 2(c) is a result of the simultaneous change of $\phi_{2}$, as described by Eq. (2).

Figure 2(d) shows the effect of a temperature decrease for a device with a good injecting anode contact and with $V_{\mathrm{bi}}=0.5 \mathrm{~V}$, assuming that $\mu$ does not depend on the temperature. The peak becomes narrower and shifts toward $V_{\text {bi }}$, as described by Eq. (1). At finite frequencies, $C_{\text {peak }}$ can decrease, as shown by the dotted lines in the figure. This happens below temperatures for which $f \tau_{\text {diff }} \approx 1$, where $\tau_{\text {diff }}=L^{2} / D$ is the characteristic time scale for diffusive transport, with $D=\left(k_{B} T / e\right) \mu(T)$ the diffusion coefficient. For a realistic MOM device with $L=100 \mathrm{~nm}$ and $\mu=$ $1 \times 10^{-10} \mathrm{~m}^{2} / \mathrm{V} \mathrm{s}$, studied at $295 \mathrm{~K}, \tau_{\text {diff }}^{-1} \approx 1 \mathrm{kHz}$. In practice, the low- $f$ limit is then easily reached. However, the fast decrease of the diffusion coefficient with decreasing temperature can already prohibit reaching the low- $f$ limit at moderately reduced temperatures.

Figure 4 (upper part) shows the frequency dependence of the capacitance for the HO device discussed already in Fig. 1, measured at room temperature. From step-height measurements using a Veeco Dektak stylus profilometer, the thickness of the LEP layer in this device was determined to be $98 \pm 5 \mathrm{~nm}$. The permittivity of the LEP layer, $\varepsilon_{r}=3.2 \pm 0.2$, was derived from the low-frequency capacitance under reverse bias, at $-1 \mathrm{~V}$. The lower part of Fig. 4 shows the results of an analysis of the experimental data, using the model parameters that most optimally render the observed frequency dependent shapes of the $C(V)$ curves and of the peak position. Using the estimated site density in the polymer, $N_{t} \approx 1.8 \times 10^{26} \mathrm{~m}^{-3}$ [10], the measured peak position, and Eq. (2), we find $\phi_{2}=1.63 \pm$ $0.05 \mathrm{eV}$. An optimal agreement with the shapes of the measured curves is obtained using $n_{1}=1 \times 10^{26} \mathrm{~m}^{-5}$, which would yield $\phi_{1} \sim 0.01 \mathrm{eV}$. The built-in voltage is thus $1.62 \pm 0.05 \mathrm{~V}$, as indicated by the arrow in Fig. 4. The model parameters used are found to justify the use of Eq. (2). The frequency dependence of the $C(V)$ curves is determined by the mobility. Excellent agreement is obtained using $\mu=1 \times 10^{-10} \mathrm{~m}^{2} / \mathrm{V} \mathrm{s}$.

Strong support for this analysis is obtained from the observation of a linear temperature dependence of $V_{\text {peak }}$ (inset), as expected from Eq. (1). First, the slope of the measured $V_{\text {peak }}(T)$ curve, $1.5 \pm 0.5 \mathrm{mV} / \mathrm{K}$, is consistent with the value of $1.04 \mathrm{mV} / \mathrm{K}$, predicted from Eq. (1). Second, the extrapolated value of $V_{\text {peak }}$ to $T=0 \mathrm{~K}, 1.7 \pm$ $0.1 \mathrm{~V}$, is consistent with the value of $V_{\mathrm{bi}}$ given above. 


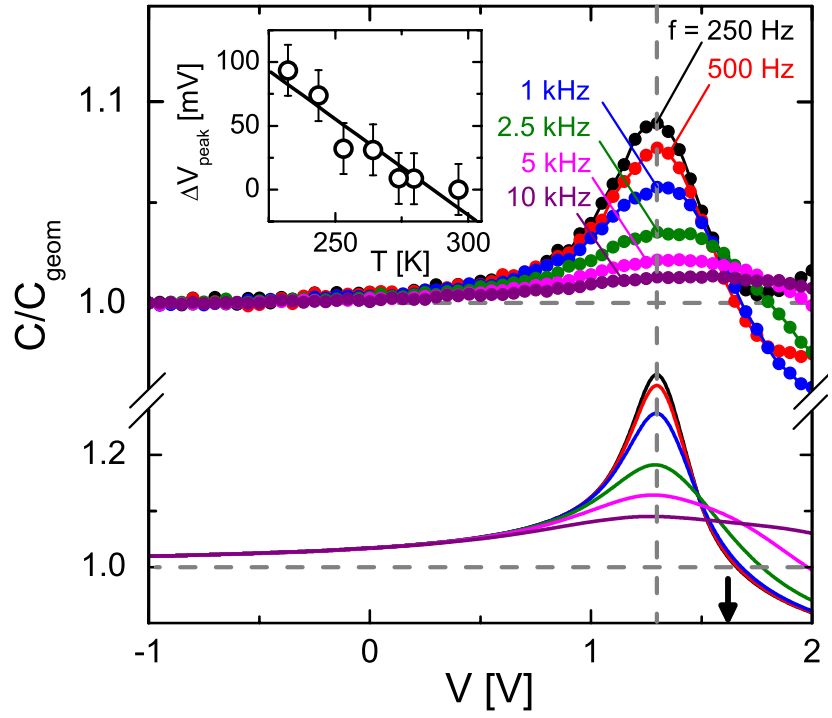

FIG. 4 (color online). Experimental (upper part) and calculated (lower part) $C(V) / C_{\text {geom }}$ curves for device $A$, at $T_{0}=$ $295 \mathrm{~K}$, with $V_{\mathrm{bi}}=1.62 \mathrm{~V}$ (arrow), $n_{1}=1 \times 10^{26} \mathrm{~m}^{-3}, \mu=$ $1 \times 10^{-10} \mathrm{~m}^{2} / \mathrm{V} \mathrm{s}$, and $\varepsilon_{r}=3.2$. The inset shows the shift of $V_{\text {peak }}$ with temperature, with respect to $V_{\text {peak }}\left(T_{0}\right)$.

For obtaining a better quantitative agreement of the peak height and width a more refined analysis will be needed. We find that a slight increase of $\phi_{1}$, to a value of $\sim 0.15 \mathrm{eV}$, would lead to a good agreement in the peak height, but would affect the agreement in the shape of the curves negatively. It will be of interest to investigate in future studies the influence of energetic disorder [12] on the peak shape. The finding of a very small value of $\phi_{1}$ is consistent with the energy diagram of the system, given in Ref. [10], from which a value $\phi_{1} \approx 0.1 \mathrm{eV}$ is expected. In contrast, $\phi_{2}$ is approximately $1.5 \mathrm{eV}$ larger than the value that would be expected from vacuum level alignment of the hole transporting units and a hypothetical clean Pd electrode surface. This is indicative of the occurrence of important organic-metal interactions at that interface, as have been revealed earlier for many other systems $[5,6]$.

We view $V_{\text {peak }}$ as an effective value of the built-in voltage. Like the onset voltage $V_{0}$ of the $J(V)$ curve [7] and like the open-circuit voltage $V_{\mathrm{oc}}$ in photovoltaic cells [15], all these voltages can be smaller than $V_{\text {bi }}$ by a few tenths of a volt due to the space charge near the electrodes. As a consequence, one also expects that the analysis of electroabsorption (EA) experiments [8] for measuring $V_{\mathrm{bi}}$ should be refined, in order to include this important correction. This is confirmed by full modeling of the EA effect for the HO devices studied in this work [16].

In conclusion, we have shown that the observed narrow peaks in the $C(V)$ curves of single-carrier MOM devices are a result of the diffusion contribution to the current density. The model presented provides a qualitatively good explanation for the peaks in our experimental $C(V)$ curves for polyfluorene-based HO devices, and it allows for a determination of both injection barriers. The peak voltage is temperature dependent, and always smaller than $V_{\mathrm{bi}}$. Refinements should be made in order to further improve the agreement of the predicted peak height and shape with experiment. An interesting application is the use of $C(V)$ measurements to monitor possible changes of injection barriers during prolonged use. Finally, we remark that this method for studying injection barriers can be extended to double-carrier OLED devices, for which peaks in the $C(V)$ curve have also been observed [9].

We would like to thank S. I.E. Vulto and J. Billen for their experimental contributions, R. A. J. Janssen, H. G. A. Huizing, and H.C.F. Martens for useful discussions, and Sumation Co., Ltd. for the supply of Lumation Blue Series polymers. This research was supported by NanoNed, a national nanotechnology program coordinated by the Dutch Ministry of Economic Affairs.

*siebe.van.mensfoort@philips.com

[1] T. D. Anthopoulos, D. M. de Leeuw, E. Cantatore, S. Setayesh, E. J. Meijer, C. Tanase, J. C. Hummelen, and P. W. M. Blom, Appl. Phys. Lett. 85, 4205 (2004).

[2] C. Wang, J. P. Snyder, and J. R. Tucker, Appl. Phys. Lett. 74, 1174 (1999); M. Dubois, D. Jiménez, P. L. de Andres, and S. Roche, Phys. Rev. B 76, 115337 (2007).

[3] I. D. Parker, J. Appl. Phys. 75, 1656 (1994).

[4] L. Chua, J. Zaumzeil, J. Chang, E.-W. Ou, P.-H. Ho, H. Sirringhaus, and R. Friend, Nature (London) 434, 194 (2005).

[5] A. Kahn, N. Koch, and W. Gao, J. Polym. Sci. B 41, 2529 (2003).

[6] C. Tengstedt, W. Osikowicz, W. Salaneck, I. D. Parker, C.-H. Hsu, and M. Fahlman, Appl. Phys. Lett. 88, 053502 (2006).

[7] M. Kemerink, J.M. Kramer, H.H.P. Gommans, and R. A. J. Janssen, Appl. Phys. Lett. 88, 192108 (2006).

[8] I. H. Campbell, T.W. Hagler, D. L. Smith, and J.P. Ferraris, Phys. Rev. Lett. 76, 1900 (1996).

[9] A. van Dijken et al., Org. Electron. 4, 131 (2003); I. N. Hulea et al., Appl. Phys. Lett. 83, 1246 (2003).

[10] R. Coehoorn, S. I.E. Vulto, S. L. M. van Mensfoort, J. Billen, M. Bartyzel, H. Greiner, and R. Assent, Proc. SPIE-Int. Soc. Opt. Eng. 6192, 619200 (2006).

[11] J. C. Scott and G. G. Malliaras, Chem. Phys. Lett. 299, 115 (1999); V. I. Arkhipov, E. V. Emelianova, Y. H. Tak, and H. Bässler, J. Appl. Phys. 84, 848 (1998).

[12] W. F. Pasveer, J. Cottaar, C. Tanase, R. Coehoorn, P. A. Bobbert, P. W. M. Blom, D. M. de Leeuw, and M. A. J. Michels, Phys. Rev. Lett. 94, 206601 (2005).

[13] J. Shao and G. T. Wright, Solid-State Electron. 3, 291 (1961).

[14] R. de Levie and H. Moreira, J. Membr. Biol. 9, 241 (1972); R. de Levie, N. G. Seidah, and H. Moreira J. Membr. Biol. 10, 171 (1972).

[15] V.D. Mihailetchi, P. W. M. Blom, J.C. Hummelen, and M. T. Rispens, J. Appl. Phys. 94, 6849 (2003).

[16] S. L. M. van Mensfoort (unpublished). 